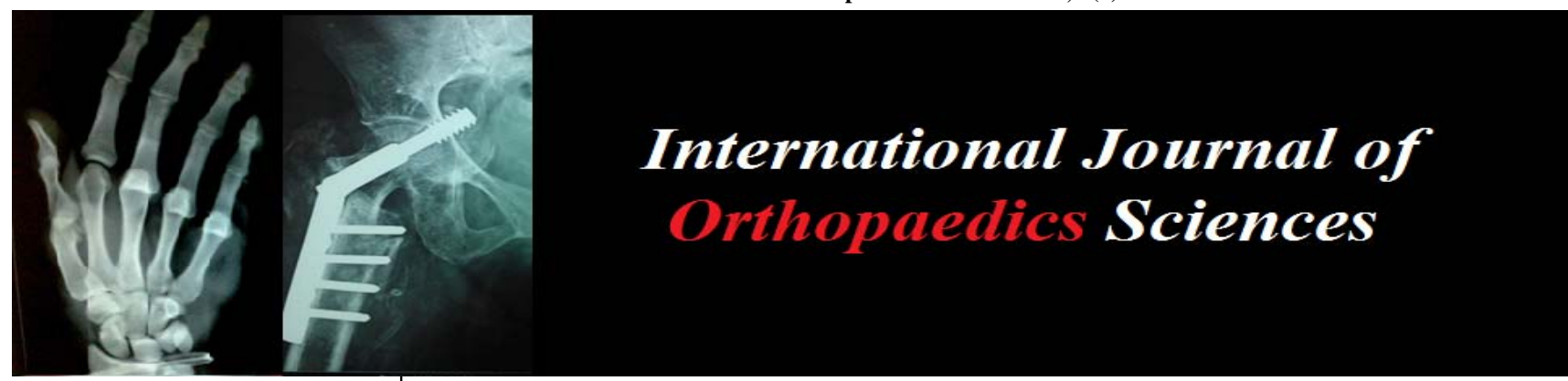

ISSN: $2395-1958$

IJOS 2017; 3(1): 111-113

(C) 2017 IJOS

www.orthopaper.com

Received: 20-11-2016

Accepted: 21-12-2016

Dr. Ashok R Nayak

Professor and Unit Chief,

BLDE University,

Shri B.M. Patil Medical College,

Vijayapur, Karnataka, India.

Dr. Arun Kumar Yamsani Smt. Bangaramma Sajjan Campus, Shri B.M. Patil Medical College, Blde University, Solapur Road, Vijayapur, Karnataka, India.

Dr. Alaf Ayub Pathan Post Graduate

BLDE University,

Shri B.M. Patil Medical College,

Vijayapur, Karnataka, India.

\section{Paraosteal osteochondromatosis proliferation (Nora's lesion) of the great toe}

\author{
Dr. Ashok R Nayak, Dr. Arun Kumar Yamsani and Dr. Alaf Ayub Pathan
}

DOI: $\underline{\text { http://dx.doi.org/10.22271/ortho.2017.v3.i1b.20 }}$

Abstract

Parosteal osteochondromatous proliferation also called Nora's lesion is a rare tumor which occurs on the proximal/distal phalanx, metacarpals, metatarsals of hand (more commonly) and feet. These lesions show $50 \%$ recurrence following excision. It has atypical histo-pathological features that must be differentiated from chondrosarcoma, low grade parosteal osteosarcoma and conventional osteosarcoma. Among benign lesions florid reactive periostitis, myositis ossificans, periosteal chondroma and osteochondroma should be considered.

Keywords: Parosteal osteochondromatosis, Nora's lesion, excision

\section{Introduction}

Benign Parosteal Osteochondromatous Proliferation (BPOP) is a rare lesion involving the small bones of the hands, feet and less often the long bones. Nora et al first described them in $1983^{[1]}$. Although, grossly these lesions resemble osteochondromas; histologically they exhibit marked proliferative activity and bizarre, enlarged and binucleate chondrocytes mimicking chondrosarcoma ${ }^{[2]}$. These lesions were confused and included with juxta-cortical osteosarcoma in the early reports. The importance of these lesions is that their aggressive histological picture and high rate of local recurrence can lead to a mistaken diagnosis of malignancy ${ }^{[3]}$.

\section{Case Report}

A $51 \mathrm{yr}$ old male patient presented to our outpatient department with complaint of painful swelling over the great toe of left foot. Patient noticed the swelling since 5years which gradually increased in size; there was no h/o trauma, no h/o pain, no interference with daily work, no h/o nocturnal pain, no h/o fever with chills, and no interference in agricultural work. Patient had pain in the swelling since 2 weeks for which he came to us.

On examination, two or three hard to firm mass measuring $4 \times 2 \mathrm{~cm}$ was present all-round the great toe [Figure.1\&2]. Range of movements of the great toe was normal. Plain X-ray of the left foot taken in Anteroposterior and oblique shows - multiple calcified masses all around proximal and distal phalanx of left great toe [Figure.3]. No articular involvement was seen, and no evidence of destruction of the bone. Routine investigations were normal and renal parameters were also normal. CT or MRI scan were not done due to pt's economic restraints. Excision biopsy was done under spinal anesthesia. A planto-medial and planto-lateral incision was taken over the great toe to expose the mass over the proximal and distal phalanx [Figure. 4]. A large calcified mass on medial aspect without attachment to bone or tendon was found at the base of proximal phalanx of the great toe. Multiple calcified small masses found on lateral aspect were also removed. No necrosis seen in the mass. There was no connection with periosteum/cortex/medulla.

Approx mass of size $4 \times 3 \mathrm{~cm}$ was removed along with small masses measuring $2 \times 2 \mathrm{~cm}$ [Figure. 5]. It was sent for histopathological examination. The surface of the mass was irregular, bosselated, whitish, and stony hard in consistency. The cut section of the mass showed gritty, stony hard, solid, white with chalky white areas. Microscopy revealed cartilaginous tissue arranged in distinctive lobulated pattern forming a cap.
Dr. Arun Kumar Yamsani Smt. Bangaramma Sajjan Campus, Shri B.M. Patil Medical College, Blde University, Solapur Road, Vijayapur, Karnataka, India 
Below it seams of bony trabeculae with marrow element in between are seen [Figure. 6]. The clinical and histopathological features of the tumour were consistent with a bizarre parosteal osteochondromatous proliferation (Nora's lesion). The patient was followed up routinely for 14 months. The tumor recurred after 2 months of excision but patient was not willing for revision surgery as the swelling did not increase in size and the patient did not have any pain or interference with daily work.

\section{Discussion}

Bizarre parosteal osteochondromatous proliferation is an uncommon reactive mineralizing mesenchymal lesion that typically affects the surfaces of bones in the hands and feet, usually the proximal and middle phalanges, and the metacarpal of hand ${ }^{[4,5]}$ and metatarsals of foot. More than 160 cases have been reported in the literature so far ${ }^{[4]}$. These lesions have a remarkable tendency to recur: recurrence rates between $29 \%$ and $55 \%$ in a 2 -year interval have been reported, and almost half of those patients have had a second recurrence. Nora and colleagues presented 35 cases of BPOP with 18 (51\%) local recurrences ${ }^{[1]}$. Meneses and colleagues reported a recurrence rate of $55 \%$ in a series of 65 patients ${ }^{[6]}$, and Dhont and colleagues reported a recurrence rate of $29 \%$ in 24 patients ${ }^{[7}$, ${ }^{10]}$. However, despite a high tendency to recur and a sometimes atypical histologic appearance, no malignant transformation, metastases, deaths or associated systemic diseases have been described so far in patients with BPOP ${ }^{[4]}$. The etiology of Nora's lesions is not known. It may be related to a reparative process following trauma to the periosteum, as this was noted in $30 \%$ of cases in the series of Meneses et al ${ }^{[8,9]}$. Ossification in BPOP resembles callus tissue at the bone cartilage interface and many authors consider trauma as a cause ${ }^{[9]}$.

Although BPOP has a characteristic clinical and histologic appearance, it may be confused with other benign and malignant lesions. Owing to the parosteal location, BPOP must be distinguished from parosteal osteosarcoma, which is rarely found in the hands and feet. The absence of cellular atypia helps to distinguish this lesion from osteosarcoma. The lesion might be mistaken for osteochondroma because of its surface location and cartilaginous component ${ }^{[3]}$. Osteochondromas are extremely uncommon in the small bones of the distal extremities ${ }^{[5]}$. They show the typical continuity with the medullary canal ${ }^{[4,6]}$ and the cartilage does not show any signs of atypia. Rybak and colleagues presented the cases of 4 patients with pathologically proven BPOP in which corticomedullary continuity with the underlying bone was demonstrated on imaging ${ }^{11}$. The absence of such a communication has been singled out as a critical imaging feature of BPOP. Rybak and colleagues indicated that BPOP could not be identified by radiologic features alone. Histopathology examination is the best method to identify this lesion and should be performed for definite diagnosis ${ }^{[11]}$.

Other benign, non-neoplastic lesions like periostitis ossificans may also simulate BPOP. This florid, reactive periostitis affects the bones of the hands in most patients, although other parts of the skeleton cannot be excluded. Turret exostosis is a dome-shaped parosteal bone proliferation located on the dorsal aspect of the phalanges. It has been proposed that BPOP, florid periostitis and turret exostosis are all part of the same lesional spectrum. The lesion may represent an intermediate lesion between florid reactive periostitis and turret exostosis. Florid reactive periostitis may progress to BPOP, as described by Dorfman and colleagues ${ }^{[12]}$.
Horiguchi and colleagues report the expression of basic fibroblastic growth factor in nearly all chondrocytes: chondromedulin-I in the tissue of the cartilaginous cap and vascular endothelial growth factor only in the large chondrocytes near the osteocartilaginous interface of the lesion. Their findings suggest that the processes occurring in the cartilaginous cap of BPOP are similar to those of enchondral ossification in the growth plate, concluding that BPOP is a reparative process after periosteal injury ${ }^{[13]}$. Immunohistochemical and molecular analysis strengthened this assumption. However, most patients do not report a history of previous trauma. Moreover, if BPOP is a reactive lesion, its remarkable tendency to recur after excision is difficult to explain.

Orui and colleagues reported the case of 1 patient with BPOP that occurred 2 years after bilateral leg erythema nodosum ${ }^{14}$. Systemic or focal inflammation might have been responsible. Zambrano and colleagues presented the cases of 3 patients with subungual (Dupuytren) exostosis and of 2 patients with BPOP. Their findings of consistent chromosomal rearrangements indicate that BPOP is a neoplastic, rather than reactive, process ${ }^{[15]}$. The cytogenetic analysis of 5 patients with BPOP by Nilsson and colleagues showed a balanced translocation $\mathrm{t}(1 ; 17)(\mathrm{q} 32 ; \mathrm{q} 21)$. To investigate the specificity of this reciprocal translocation, they screened the karyotypes of more than 43000 neoplasms and found no identical translocation. It seems to be a recurrent and pathogenetically significant aberration in BPOP [16]. Endo and colleagues described the case of a 39-year-old woman with BPOP arising in the proximal phalanx of her third toe. Their cytogenetic analysis is comparable with the findings of Nilsson and colleagues. The occurrence of a translocation, as mentioned previously, supports the assumption that a neoplastic process may be the etiologic agent.

The true prevalence of BPOP is difficult to assess because most lesions are reported in case studies and because larger, mostly histologic studies are retrospective. Therefore, further work is needed to fully elucidate the etiology of BPOP.

Excision is the recommended therapy of symptomatic BPOP [4]. Intralesional excision seems to have a great potential for local recurrence, but it preserves stability without decortication of the affected bone. En bloc negative margin excision by the excision of the pseudo capsule over the lesion and any periosteal tissue beneath the lesion and the decortication of any areas in the underlying host bone that appear abnormal has been shown to be beneficial in preventing local recurrence ${ }^{[4]}$. Wide resection could possibly lead to segmental amputation because of the anatomic conditions in the long bones of the fingers and toes, and it cannot be recommended as first-line surgical treatment ${ }^{[6,7]}$.

Though it shows high rate of recurrence no malignant transformation, metastasis, deaths or associated systemic illnesses have been seen in patients with Nora's lesion. Owing to high local recurrence rates and a lack of adjuvant therapy options, the Nora lesion will continue to pose a challenge for orthopedic surgeons and clinical research.

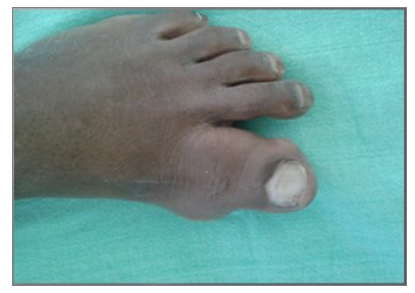

Fig 1 


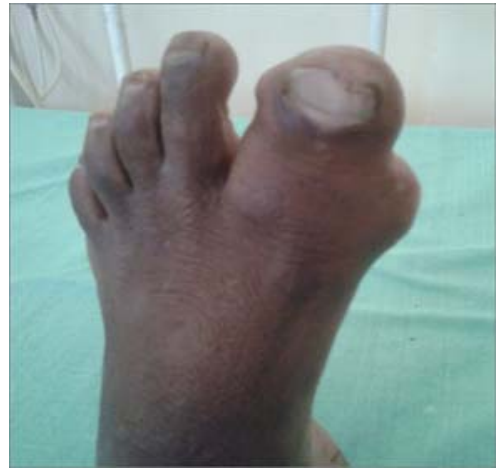

Fig 2

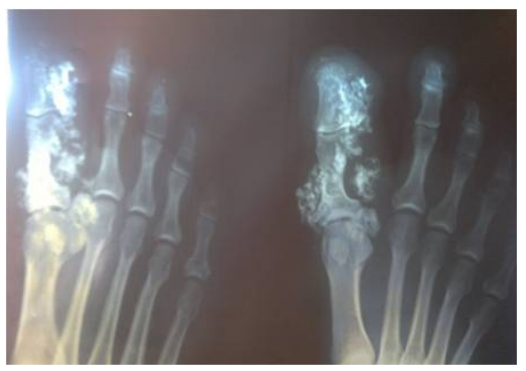

Fig 3

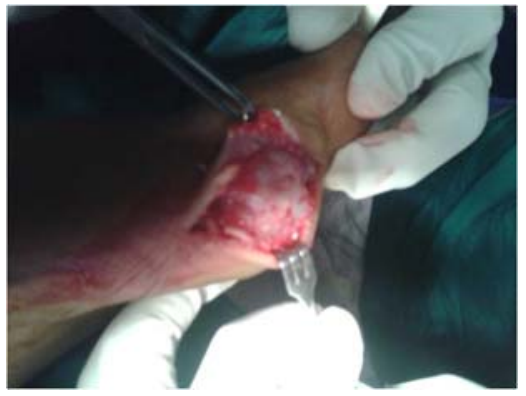

Fig 4

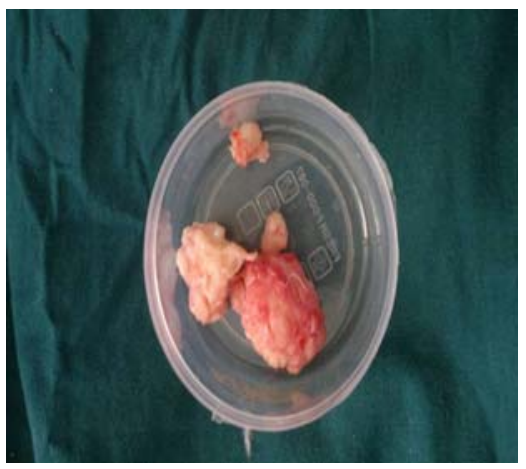

Fig 5

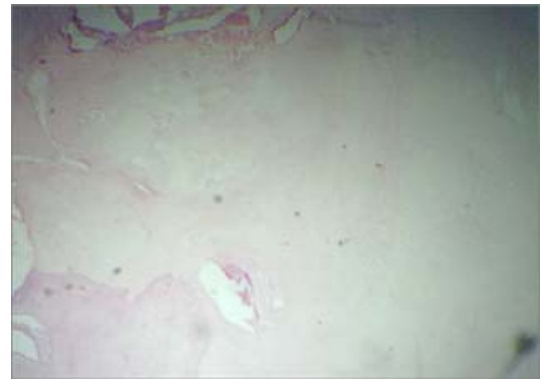

Fig 6

\section{References}

1 Nora FE, Dahlin DC, Beabout JW. Bizzare parosteal osteochondromatous proliferations of hand and feet. Am J Surg Pathol 1983; 7:245-250.

2 Soon JL, Chang HC, Sim CS. A case of bizzare parosteal osteochondromatous proliferation of the hand. Sing Med J. 2003; 44:027-030.

3 Stark HH, Jones FE, Jernstrom P. Parosteal osteogenic sarcoma of a metacarpal bone. J Bone Joint Surg Am. $1971 ; 53: 47-53$.

4 Gruber G, Glessauf C, Leithner A. Bizarre parosteal osteochondromatous proliferation (Nora's lesion): a report of 3 cases and a review of literature. Can J Surg 2008; 51:486-489.

5 Davies CWT. Bizarre parosteal osteochondromatous proliferation in the hand: A case report. J Bone Joint Surg (Am). April 1985; 67-A(4):648-50.

6 Meneses MF, Unni KK, Swee RG. Bizarre parosteal osteochondromatous proliferation of bone (Nora's lesion). Am J Surg Pathol. 1993; 17:691-7.

7 Torreggiani WC, Munk PL, Al-Ismail K, O’Connell JX, Nicolaou S, Lee MJ, Masri BA. MR imaging features of bizarre parosteal osteochondromatous proliferation of bone (Nora's lesion). Eur J Radiol. 2001; 40:224-231.

8 Yuen M, Friedman L, Orr W, Cockshott WP. Proliferative periosteal processes of phalanges: a unitary hypothesis. Skeletal Radiol. 1992; 21:301-303.

9 Lindeque BG, Simson IW, Fourie PA. Bizarre parosteal osteochondromatous proliferation of a phalanx. Arch Orthop Trauma Surg. 1990; 110:58-60.

10 Dhondt E, Oudenhoven L, Khan S. Nora's lesion, a distinct radiological entity? Skeletal Radiol. 2006; 35:497502.

11 Rybak LD, Abramovici L, Kenan S. Cortico-medullary continuity in bizarre parosteal osteochondromatous proliferation mimicking osteochondroma on imaging. Skeletal Radiol. 2007; 36:829-34.

12 Dorfman HD, Czerniak B. Bone tumors. St. Louis (MO): Mosby, 1998.

13 Horiguchi H, Sakane M, Matsui M. Bizarre parosteal osteochondromatous proliferation (Nora's lesion) of the foot. Pathol Int 2001; 51:816-23.

14 Orui H, Ishikawa A, Tsuchiya T. Magnetic resonance imaging characteristics of bizarre parosteal osteochondromatous proliferation of the hand: a case report. J Hand Surg [Am] 2002; 27:1104-8.

15 Zambrano E, Nose V, Perez-Atayde AR. Distinct chromosomal rearrangements in subungual (Dupuytren) exostosis and bizarre parosteal osteochondromatous proliferation (Nora lesion). Am J Surg Pathol. 2004; 28:1033-9.

16 Nilsson M, Domanski HA, Mertens F. Molecular cytogenetic characterization of recurrent translocation breakpoints in bizarre parosteal osteochondromatous proliferation (Nora's lesion). Hum Pathol 2004; 35:10639. 